\title{
Análise do potencial do melaço como novo subproduto na indústria da soja
}

\author{
Grijó, D. R. ${ }^{1^{*}} ;$ Melo, B. N. ${ }^{2}$ \\ 1 Programa de Pós-Graduação em Engenharia Química, Universidade Estadual de Maringá, Maringá, PR, Brasil. \\ 2 Departamento de Ciências Naturais, Universidade Federal do Espírito Santo, São Mateus, ES, Brasil. \\ *e-mail: pg49313@uem.br
}

\begin{abstract}
Resumo
O Brasil é um grande produtor de oleaginosas, e a soja se destaca como uma delas. A principal aplicação industrial deste insumo é a produção de óleo gerando o farelo, rico em proteínas e carboidratos, como importante subproduto, aplicado principalmente em ração animal. Os carboidratos são formados por estruturas chamadas de monossacarídeos (MS). Atualmente vem sendo analisado a geração de um novo subproduto, conhecido como melaço, rico em MS e produzido pela lavagem do farelo com solução de etanol. Neste trabalho foi analisado o teor de carboidratos por espectrofotometria com absorção em 490 $n m$ e utilizando uma curva de calibração de glicose com linearidade $R^{2}=0,9995$. Na matéria prima inicial, além do teor de carboidratos (31,50\%), também foram calculados a umidade $(8,00 \%)$, cinzas $(4,89 \%)$ e lipídeos $(20,22 \%)$, possibilitando a análise de proteínas $(35,39 \%)$ por diferença. O melaço apresentou uma composição seletiva de carboidratos, mantendo assim o valor nutricional de proteínas e carboidratos fibrosos no farelo concentrado, que é aplicado também como ração animal. Com isso, concluiu-se que o melaço possui potencial de novo subproduto na indústria da soja sem alterar as atuais aplicações. Esta metodologia demonstra também grande potencial para analisar outras oleaginosas.
\end{abstract}

\begin{abstract}
Brazil is a big producer of oil, and soybean stands out as one of them. The main industrial application of this input is the production of oil generating bran, high in protein and carbohydrates, as an important byproduct, used mainly as animal feed. Carbohydrates are formed by structures called monosaccharide (MS). It is currently being considered the generation of a new byproduct, known as molasses, high in MS and produced by washing bran with ethanol solution. This work analyzed the carbohydrate content by spectrophotometry with absorption at $490 \mathrm{~nm}$ and using a glucose calibration curve with $\mathrm{R}^{2}=0.9995$ linearity. In the initial raw material, in addition to the carbohydrate content (31.50\%), were also calculated moisture (8.00\%), ash (4.89\%) and lipids (20.22\%), allowing the analysis of proteins (35.39\%) by difference. The molasses had a selective carbohydrate composition, thus maintaining the nutritional value of protein and fibrous carbohydrates in the concentrate bran, which is applied also as animal feed. Thus, it was concluded that the molasses has potential new-product in the soy industry without changing the current applications. This methodology also demonstrates great potential for examining other oilseeds.
\end{abstract}

Keywords (Palavras chaves): carbohydrates, spectrophotometry, oilseeds.

\section{Introdução}

Historicamente, a soja foi introduzida no Brasil por imigrantes chineses e japoneses no final do século XIX e, já no século $X X$, ganhou incentivos para o seu cultivo devido ao grande interesse industrial pelo seu expressivo teor de óleo e proteína ${ }^{[1]}$. Devido a constante evolução da cultura no país ${ }^{[2]}$, avaliar novos subprodutos torna-se algo importante.

A composição da soja é baseada em cinco componentes: umidade, proteína, lipídeos, carboidratos e cinzas. Os conteúdos em menor quantidade são as cinzas $(4,45 \sim 6,60 \%)$ e a umidade $(5,35 \sim 6,62 \%){ }^{[3]}$, porém a umidade pode representar um valor maior, por exemplo, 13\%, quando o grão é estocado ${ }^{[4]}$. No entanto, apresentam alto teor de lipídeos (15 $25 \%$ ), proteínas $(30 \sim 45 \%)$ e carboidratos $(20 \sim 35 \%)^{[5]}$,

Os carboidratos são formados por estruturas chamadas monossacarídeos (MS). Dois MS, unidos por uma ligação chamada de glicosídica, foram os dissacarídeos (DS), 3 a 10 os oligossacarídeos (OS) e quantidade superior os polissacarídeos (PS) ${ }^{[6]}$. Os carboidratos presentes na soja, aproximadamente, são: $5 \%$ de sacarose (DS), 1,1 \% de rafinose (OG), 3,8\% de 
estaquiose (OS), $4 \%$ de celulose (PS), $15 \%$ de hemicelulose (PS) e $5,1 \%$ de outros ${ }^{[7]}$. Alguns dos carboidratos presentes em pequenas quantidades são: glicose (MS), galactose (MS) ${ }^{[8]}$, frutose (MS) e amido (PS) ${ }^{[9]}$. Os monossacarídeos são classificados de acordo com o número de átomos de carbono na cadeira principal ${ }^{[10]}$, sendo os mais importantes formados por cinco (pentoses) ou seis (hexoses) ${ }^{[11]}$.

A principal aplicação industrial do grão da soja é na produção de óleo gerando o farelo como subproduto. 0 farelo é muito utilizado como ração animal ${ }^{[12,13]}$ e atualmente vem sendo analisado a geração de um novo subproduto rico em MS a partir deste, conhecido como melaço, pela lavagem com solução de etanol ${ }^{[8,9]}$. Este processo industrial pode ser aplicado, por exemplo, na produção de etanol em quantidade muito maior ao usado, gerando potencial a indústria ${ }^{[14]}$.

Uma forma de analisar o potencial de uma matériaprima gerar MS é utilizando a Reação de Molisch ${ }^{[15]}$, onde o ácido sulfúrico hidrolisa as ligações glicosídicas e desidrata as pentose em furfural e hexoses em hidroximetilfurfural, como demonstrado na Figura $1^{[11]}$.

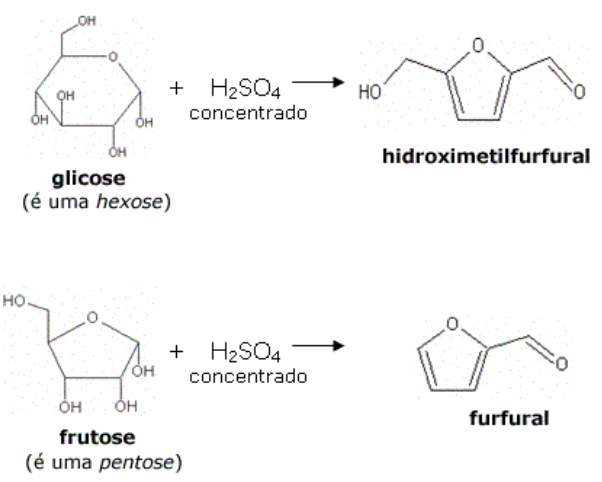

Figura 1 - Reação de Molisch.

Os produtos desta reação, quando reagem com fenol ou derivado, como, por exemplo, antrona ou naftol, produzem compostos coloridos [16] que podem ser detectados por espectrofotometria $[17,18,19]$. A intensidade da cor (laranja-marrom) formada é proporcional à quantidade de MS na amostra ${ }^{[20]}$. Utiliza-se para esse processo o espectrofotômetro que afere a absorbância do analito. De maneira geral, a concentração do analito está relacionada linearmente com a absorbância, respeitando para esta valores menores que um, de acordo com a Lei de Beer, pois nestas concentrações a distância média entre as moléculas não afeta a vizinhança ${ }^{[21]}$.

Este trabalho tem como objetivo analisar o potencial de carboidratos, na forma de MS (monossacarídeos), presentes no melaço da soja.

\section{Materiais e Métodos}

Este trabalho foi realizado no Centro Universitário Norte no Espírito Santo, da Universidade Federal do Espírito Santo (CEUNES/UFES), entre Março a Julho de 2015.

\subsection{Obtenção e Preparo de amostra}

A amostra de soja foi adquirida no mercado local da cidade e pré-selecionada, eliminando-se os grãos indesejáveis pelo método de catação. Separou-se uma amostragem de $100 \mathrm{~g}$ de grãos que seguiu para a trituração utilizando um liquidificador doméstico.

\subsection{Determinação do Teor de Umidade}

A porcentagem de umidade foi determinada em duplicata usando-se o seguinte procedimento: as amostras foram deixadas em equilíbrio com a umidade e temperatura ambiente por 44 horas, em sistema aberto. Em placas de Petri, previamente taradas, foram pesadas aproximadamente $1,0 \mathrm{~g}$ de soja triturada e em seguida foram levadas à estufa, a $105^{\circ} \mathrm{C}$, por aproximadamente 2,5 horas. Após este procedimento as amostras foram resfriadas em dessecador com sílica e pesadas até massa constante.

\subsection{Determinação do Teor de Cinzas}

O teor de cinzas, ou inorgânicos, for calculado pela norma TAPPI T-211 om-85 [22]. Primeiramente os cadinhos de porcelana foram aquecidos a $600^{\circ} \mathrm{C}$ em mufla (Fornitec, F2DM) por uma hora e resfriados em dessecador, até massa constante. Em duplicata as amostra de soja foram então pesadas, cerca de $1,0 \mathrm{~g}$, e procedeu-se a combustão lenta a $600 \stackrel{\circ}{\circ}$ por 4 horas. As amostras calcinadas foram resfriadas em dessecador até massa constante, e posteriormente determinou-se o teor de cinzas.

\subsection{Extração do óleo}

A extração do óleo da soja foi realizada em apenas um procedimento, seguindo a metodologia de Hara-Folch $(1978)^{[23]}$. Utilizou-se uma mistura hexano (Proquimios) e isopropanol (Isofar) na proporção 3:2. Em um erlenmeyer de $250 \mathrm{~mL}$ colocou-se aproximadamente $8,0 \mathrm{~g}$ da soja triturada e $150 \mathrm{~mL}$ da mistura extratora. $\mathrm{O}$ sistema foi mantido sob agitação magnética por $1 \mathrm{~h}$. Após este tempo, a suspensão foi centrifugada (HT, 802B) a $3000 \mathrm{rpm}$ por 15 minutos. O líquido sobrenadante foi separado e o sólido (farelo) esgotado por mais duas lavagens de mesmo volume com a mistura de solventes, sendo a agitações magnéticas e centrifugações mantidas apenas por $10 \mathrm{~min}$. 
O óleo foi recuperado por evaporador rotativo (Quimis, G344B2) utilizando um balão previamente pesado. O farelo foi posto em uma placa de Petri e seco em uma estufa a $80 \stackrel{\circ}{ } \mathrm{C}$ aproximadamente por $0,25 \mathrm{~h}$.

\subsection{Extrações dos carboidratos}

Os carboidratos foram analisados em diferentes fases do processo como demonstrado a Figura 2.

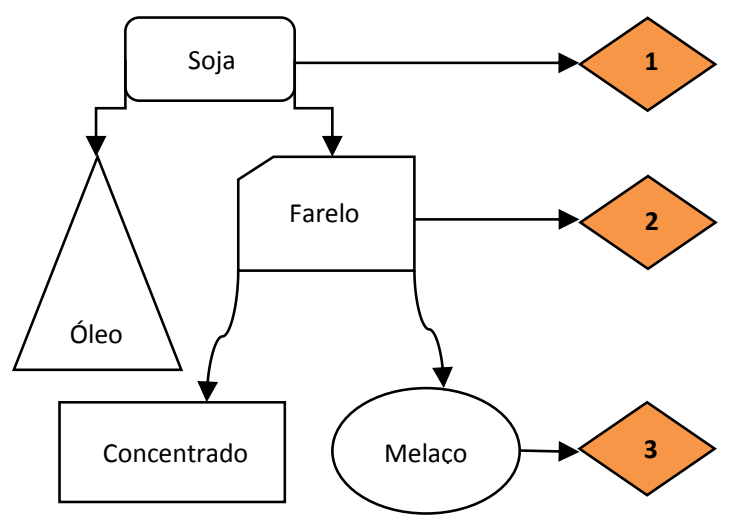

Figura 2 - Etapas de amostragem de análises.

A determinação dos carboidratos foi conduzida em duplicata. Para as análises 1 e 2, aferiu-se aproximadamente $200 \mathrm{mg}$ de amostra em erlenmeyers de $500 \mathrm{~mL}$ e adicionou-se $200 \mathrm{~mL}$ de água destilada em cada uma. Para a obtenção do melaço, aproximadamente $1,0 \mathrm{~g}$ do farelo desengordurado foi aferido em um erlenmeyer de $250 \mathrm{~mL}$ adicionou-se 100 $\mathrm{mL}$ de etanol $70 \%$. Em seguida todos os erlenmeyers foram mantidos sob agitação magnética durante $1 \mathrm{~h}$. Após a agitação, filtrou-se, a vácuo, cada amostra separadamente recolhendo os precipitados em placas Petri e acondicionando os filtrados em balões volumétricos. Os sólidos foram secados em estufa a $105^{\circ} \mathrm{C}$ por $4 \mathrm{~h}$ e resfriados em dessecador até peso constante.

\subsection{Determinações dos carboidratos}

A determinação dos carboidratos solúveis seguiu-se a metodologia descrita por Dubois (1956) ${ }^{[24]}$, ou seja, reagir $0,5 \mathrm{~mL}$ de amostra com $2,5 \mathrm{~mL}$ de ácido sulfúrico concentrado e em seguida reagiu com $0,5 \mathrm{~mL}$ de fenol. Esta reação gera um composto colorido de fenolaldeido que apresenta absorção máxima em $490 \mathrm{~nm}{ }^{[17,}$ ${ }^{18]}$. Para esta determinação se faz necessário a construção de uma curva padrão.

A curva padrão foi obtida utilizando soluções aquosas de glicose nas concentrações de 0,$08 ; 0,16 ; 0,20$ $\mathrm{mg} / \mathrm{mL}$. Para cada solução padrão conduziu a reação com ácido sulfúrico concentrado e fenol. A medida das absorbâncias máximas foi obtida utilizando um espectrômetro (Thermo Scientific, G10S UV-Vis) colocando as soluções em uma cubeta de vidro com caminho ótico de $1 \mathrm{~cm}$ e fazendo as leitura no comprimento citado anteriormente.

As amostras dos extratos da soja foram analisadas seguindo a mesma metodologia, Porém, para ajuste a curva padrão, as amostras 1 e 2 tiveram que ser diluídas duas vezes e o melaço em dez vezes.

\section{Resultados e Discussões}

As caracterizações preliminares obtidas da soja como teor de umidade, cinzas e óleo estão na Tabela 1. Os valores foram próximos aos descritos na referência.

Tabela 1 - Caracterização da soja

\begin{tabular}{|c|c|c|}
\hline Teor de óleo & Teor de cinzas & Teor de umidade \\
\hline $20,22 \%$ & $4,89 \%$ & $8,00 \%$ \\
\hline
\end{tabular}

O Gráfico 1 apresenta a curva padrão utilizada para a determinação quantificação dos monossacarídeos.

Gráfico 1 - Curva padrão de glicose.

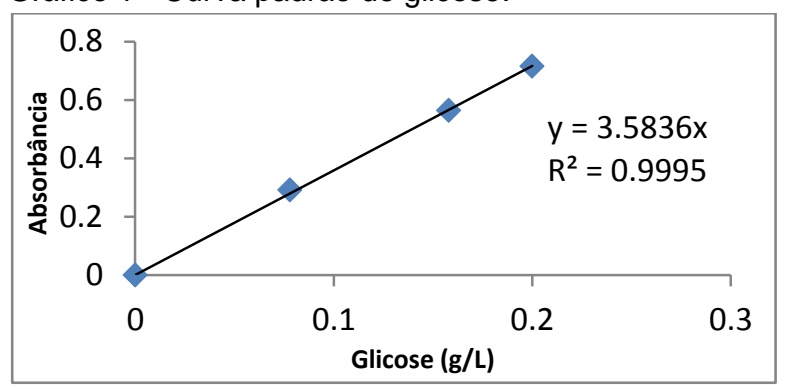

A Tabela 2 apresenta o teor de monossacarídeos encontrados na soja inicial, no farelo e no melaço.

Tabela 2 - Teores de monossacarídeos nas análises.

\begin{tabular}{|c|c|c|}
\hline Soja inicial & Farelo & Melaço \\
\hline $0,34 \pm 0,03(\mathrm{~g} / \mathrm{L})$ & $0,28 \pm 0,02(\mathrm{~g} / \mathrm{L})$ & $2,08 \pm 0,09(\mathrm{~g} / \mathrm{L})$ \\
\hline $31,5 \pm 0,60 \%$ & $27 \pm 1,00 \%$ & $20,77 \pm 0,01 \%$ \\
\hline
\end{tabular}

A extração aquosa da soja inicial apresentou um valor maior que a extração aquosa do farelo. Este fato pode ser explicado devido à etapa de retirada do óleo ter tornado o insumo mais compacto, o que dificultou seu inchamento. O melaço apresentou uma composição mais seletiva de carboidratos, mantendo assim o valor nutricional de carboidratos maiores, ou seja, polissacarídeos fibrosos, no farelo concentrado, aplicado também em ração animal ${ }^{[8,14]}$. Uma curva de calibração de glicose em etanol $70 \%$ resultaria em uma análise mais eficiente do teor de carboidratos no melaço. 


\section{Conclusões}

O estudo comprovou o teor de lipídeos, proteínas, carboidratos, cinzas e umidade da soja dentro do descrito na literatura. Observou-se que com a água foi possível extrair grande parte de carboidratos da soja. A boa eficiência da água como solvente se demonstrou previamente devido ao esbranquiçamento da solução e já era esperada visto que este insumo é uma matéria prima importante para a produção de bebidas a base de carboidratos.

Apesar de menos polar, o etanol se demonstrou vantajoso pelo fato de selecionar apenas carboidratos menores, possibilitando que a composição do farelo concentrado seja rica em proteínas e carboidratos maiores, ou seja, fibras. Com isso, o melaço se demonstra com uma possível viabilidade de produção de produtos como etanol, visto que uma pequena quantidade de ácido será requerida para a hidrólise.

Uma alternativa importante para se tentar a extração completa dos carboidratos é analisar um procedimento sob pressão com água quente, porém é necessário cautela, pois a alta temperatura desnatura as proteínas.

Devido à importância nutricional da soja no Brasil, mais análises devem ser feitas afim de melhor avaliar 0 estudo. Esta metodologia também demonstra grande potencial para analisar oleaginosas.

\section{Agradecimentos}

Os autores agradecem ao Departamento de Engenharia e Tecnologia (DETEC/CEUNES/UFES), em especial a coordenadora, em data, do Curso de Graduação em Engenharia Química, Professora Doutora Ana Beatriz Neves Brito, pela oportunidade de pesquisa, bem como a Professora Doutora Márcia Helena Rodrigues Velloso, do Departamento de Ciências Naturais (DCN/CEUNES/UFES), por disponibilizar o uso do Laboratório de Química Orgânica do CEUNES/UFES.

\section{Referências}

${ }^{[1]}$ RIVAS, M. B. Soja - Qualidade de vida e saúde com prazer e sabor. Ed. AGE, 2006.

${ }^{[2]}$ Ministério da Agricultura Pesca e Abastecimento. Plano Agrícola e Pecuário 2013/2014. Secretaria de Política Agrícola. Brasília/DF. Disponível em: <http://www.agricultura.gov.br/arq_editor/file/acs/PAP2 0132014-web.pdf>. Acesso em: 22 Set, 2016.

${ }^{[3]}$ ALVES, D. P.; et al. Composição centesimal de grãos de soja de oito diferentes cultivares; Universidade Tecnológica Federal do Paraná. Embrapa Soja.
Documentos, 328. VI Jornada Acadêmica da Embrapa Soja, 2011.

${ }^{[4]}$ LIU, K. "Soybeans: Chemistry, Technology and Utilization", Aspen Publishers Inc. Gaithersburg, Maryland, 1999.

${ }^{[5]}$ MOREIRA, A. M. Programa de melhoramento genético da qualidade de óleo e proteína da soja desenvolvido na UFV. Congresso Brasileiro de Soja, Londrina, PR, Anais, p.99 104, 1999.

${ }^{[6]}$ MORETTO, E.; et al. Introdução à ciência de alimentos. Editora UFSC, 2002.

${ }^{[7]}$ KAWAURA, S. Review of PL 480 work on soybean carbohidrates. In: International Conference of soybean protein foods. Peoria, Illinois. Proceedings, Washington DC, U.S. Department of Agriculture, 1967. p.4. 249-54 (ARS-71-35), 1966.

${ }^{[8]}$ FERNANDES, G. R.; MIGUEL, D. P. Detecção dos açúcares da soja. FAZU - Indústria de alimentos. UNESP, alimentos e nutrição, 2011.

${ }^{[9]}$ OLIVEIRA, M. A.; et al. Quantificação dos teores de açúcares, oligossacarídeos e amido em genótipos/cultivares de soja (Glycine Max (L) Merril) especiais utilizados para alimentação humana. Braz. J. Food. Technol., Campinas, V. 13, n.1, p.23-29, 2010.

${ }^{[10]}$ CAREY, F. A. Química Orgânica. Sétima edição. Volume 2. Universidade da Virgínia, 2011.

${ }^{[11]}$ SOUSA, E. S. Identificação de Carboidratos. Faculdade Católica de Tocantins. Curso de Agronomia. Bioquímica geral, 2011.

${ }^{[12]}$ CORDEIRO, A. Sustainable Agriculture in Global Age: Lessons from Brazilian. Agriculture. Swedish Society for Nature Conservation. BGAB, Estocolmo, Suécia, 2000.

${ }^{[13]}$ GELDER, J. W.; DROS, J. M. From rainforest to chicken breast: Effects of soybean cultivation for animal feed on people and nature in the Amazon region - a chain of custody study. Research report for the Dutch Soy Coalition commissioned by Friends of the Earth Netherlands and Cordaid, 2004.

${ }^{\left[{ }^{14]} R O M A ̃ O, ~ B . ~ B . ~ P r o d u c ̧ a ̃ o ~ d e ~ e t a n o l ~ p o r ~ h i d r o ́ l i s e ~\right.}$ ácida de melaço de soja. Universidade Federal de Uberlândia. Faculdade de Engenharia Química. Programa de Pós-graduação em Engenharia Química), 2011.

${ }^{[15]}$ MEYER, L. H. Food Chemistry Reinhold Pub. Co., NY, 1960. 
${ }^{[16]}$ ASLT. Analytical Standards, Laboratory Techniques. Lactose Determination - Comission E. IOF $61^{\text {st }}$ Annual Session, 1977.

${ }^{[17]}$ REIS, C. C. Comparação entre técnicas para determinação de açúcares solúveis em alimentos utilizados na nutrição de ruminantes. Trabalho de Conclusão de Curso. Zootecnia. Universidade Tecnológica Federal do Paraná, 2011.

${ }^{[18]}$ DEMIATE, I. M.; et al. Determinação de açúcares redutores totais em alimentos. Comparação entre métodos colorimétricos e titulométricos. Exact and soil sciences. Agrarian S. and Engeneering, 8(1): 65 - 78, 2002.

${ }^{[19]}$ DERIAZ, R. E. Routine analysis of carbohydrate and lignin in herbage. Jounal of Science and Food Agriculture, v.12, p.150-160, 1961.
${ }^{[20]}$ EPAMG. Empresa de Pesquisa Agropecuária de Minas Gerais. Revista do Instituto de laticínios Cândido Tostes. Diary magazine published bimonthly, 1978.

${ }^{[21]}$ SKOOG, D. A. et al. Princípios de Análise Instrumental. 5 $5^{\underline{a}}$ ed. Bookman, Porto Alegre, 2002.

${ }^{[22]}$ TAPPI. Technical association of the pulp and paper industry. Test methods. Atlanta: TAPPI Press, 1999.

${ }^{[23]}$ HARA, A., NORMAN, S. R. Lipid Extraction of Tissues with a Low-Toxicity Solvent. Mental Health Reaserch Institute and Department of Biological Chemistry, University of Michiganm. AnalyticalBiochemistry 90, 420-426, 1978.

${ }^{[24]}$ DUBOIS, M. et al. Colorimetric Method for determination of sugars and related compounds. Analytical Chemistry, v.28, n.3, p350 356, 1956. 